\title{
Using spatial econometrics to test for collusive behavior in procurement auction data
}

\author{
Mats A. Bergman ${ }^{1}$, \\ Johan Lundberg ${ }^{2}$, \\ Sofia Lundberg ${ }^{2}$ \\ Johan Y. Stake ${ }^{1}$
}

\begin{abstract}
In this paper we evaluate whether spatial econometric techniques can be used to test for collusive bidder behavior in public procurement auctions, using the submitted bids and procurement characteristics. The proposed method is applied to the so-called Swedish asphalt cartel, which was discovered in 2001. As our dataset covers the period 1995-2009, we are able to test for conditional independence between complementary cartel bids before and after the detection. Our estimates show a significant positive correlation between complementary cartel bids during the cartel period, whereas a non-significant (and negative) correlation is shown during the later period. The parameter estimate of interest also differs in magnitude between periods. Hence, we argue that the method suggested can be used to verify or possibly screen for collusive bidding behavior. The main advantage of this method is its relatively small data requirements.
\end{abstract}

JEL-codes: D44, H57, L10, L40

Key-words: Antitrust, Auction, Cartel, Collusion, Complementary bidding, Public procurement, Spatial econometrics, Road re-pavement

\footnotetext{
${ }^{1}$ Department of Economics, Södertörn University, 14189 Huddinge, Sweden.

2 Department of Economics, Umeå School of Business and Economics, Umeå University, 90187 Umeå, Sweden.

The authors would like to thank the Swedish Competition Authority and the Swedish Research Council for financial support.
} 


\section{Introduction}

Early on October 24, 2001, under the cover of darkness, the Swedish Competition Authority (SCA) conducted unannounced raids on a number of companies in the Swedish asphalt paving industry. The purpose of the raids, which continued for two days, was to find documents that could verify suspicions of illegally collusive bidding on public contracts. A large number of documents were seized and key employees of the companies were questioned. These events marked the beginning of the largest cartel investigation ever in Swedish history, eventually producing ten shelf-meters of documents. The trials at the Stockholm District Court lasted more than 40 days and more than 70 persons were questioned. ${ }^{3}$ On July 10, 2007, the court ordered nine companies to pay more than SEK 1.2 billion or $€ 133$ million in fines.

The main objective of this paper is to show how spatial econometric techniques can be used to detect non-independent bidding between cartel members. The econometric model is applied to data on public procurements of asphalt paving before and after 2002, where we seek to establish whether such techniques can be used to confirm collusive bidding before 2002. The hypotheses to be tested is whether, conditional on other potentially important determinants, bids placed by one cartel member $i$ correlate with bids placed by cartel member $j$ on the same contract, $c$, auctioned in one and the same procurement, $p$.

A spatial weights matrix, based on priors linked to this hypothesis, is used to identify bids that are likely to be correlated with each other, i.e., the bids from the cartel members. The parameter estimates in the empirical model can be interpreted as slope parameters of reaction curves between firms that place bids on the same contract. This follows broadly the same principle as in Porter and Zona (1993) and Bajari and Ye (2003). In the absence of collusive bidding and after controlling for publicly available information, bids placed by one firm should be uncorrelated with bids placed by all other firms. ${ }^{4}$

Our results indicate collusive bidding among cartel members before 2002, while the relevant parameter is insignificant and differ (significantly so for most specifications) in magnitude after 2003, consistent with non-collusive bidding. However, we are the first to admit and realize that the results and methods described here require accompanying evidence and other types of proof to hold in court. However, we do argue that this relatively simple method, which requires a minimal amount of data, could be used to screen for collusion. If this method shows significant non-

\footnotetext{
${ }^{3}$ According to the Swedish Competition Authority (SCA), the four largest companies in the asphalt paving industry met secretly several times per year. At these meetings, the companies agreed on how they would divide state, municipal and private contracts between them and also exchanged information on prices and volumes. The group distributed missions consistent with business concerns and market share. Companies not included in the group, and thus potential competitors, were compensated to abstain from bidding or to place a bid so high that they would not win the contract.

${ }^{4}$ Unless there are unobserved variables that cause correlation.
} 
independence of bids, competition authorities could proceed to make further investigations into the possibility of a cartel.

The development of empirical methods to detect collusive bidding has gained increased attention, especially from economists. See Bajari and Summers (2002) and Harrington (2008) for a literature review. Most of these studies have been based on actual cases, where the identity of the cartel members is known to the researcher, and where the challenge has been to econometrically confirm the cartel by a comparison of bids submitted by cartel and non-cartel members (e.g., Porter and Zona, 1993, 1999; Pesendorfer, 2000). In addition to these papers, Bajari and Ye (2003) provide an approach where asymmetries among bidders are also accounted for. The analysis accounts for differences in observable characteristics between the firms in terms of geographical location and production technology.

This paper contributes to the existing empirical literature by introducing a new econometric approach to test for collusion: spatial regression techniques (see Anselin, 1988; Anselin and Bera, 1998; LeSage and Pace, 2009; Elhorst, 2014). To our knowledge, these techniques have never before been used to test for collusion in the way proposed in this paper. The advantage of our model is the modest data requirement and the simple estimation techniques compared to tests used previously. This paper also serves as a complement to previous studies which, for the most part, are based on U.S. data.

The rest of this paper is organized as follows. Section 2 provides an overview of previous literature, followed by specific features of the procurements studied in Section 3. Section 4 presents our data, and the econometric setup and specification are presented in Section 5. The results are presented and discussed in Section 6 and concluding remarks are given in Section 7.

\section{Previous literature}

Despite cartels being prohibited by law, evidence of coordinated bidding in public procurement auctions has been found in numerous markets. In addition to the Swedish asphalt cartel, also analyzed by Jakobsson (2007a; 2007b), cartels have been found in public procurement auctions of, i.e., frozen seafood (Froeb, Koyak and Werden, 1993), school milk (Pesendorfer, 2000; Porter and Zona, 1999; Lee, 1999), highway construction (Porter and Zona, 1993; Gupta, 2001), highway repair (Bajari and Ye, 2003) and public works (Lee and Hahn, 2002).

Grout and Sonderegger (2005) summarize the theoretical predictions of what increases the probability of collusion, which include high entry barriers, a small number of rivals and symmetry among them in terms of cost and quality. Based on empirical evidence drawn from detected cartels, Levenstein and Suslow (2006) find the average cartel lifespan to be about five years; 
many break up in less than a year, while others last for at least five to ten years. They conclude that the biggest threats to a cartel tend to arise when it tries to adapt to changing economic conditions. Connor and Bolotova (2006) perform a meta-study regression analysis that aims to explain cartel overcharges. They find that overcharges tend to be significantly higher for international cartels and that duration, legal environment and organizational characteristics explain many of the variations.

Other examples of empirical studies within this field are Cramton and Schwartz's $(2000,2002)$ study of spectrum auctions and Gupta's (2001, 2002) study of highway construction procurements in the U.S. and competition and bidder interaction. Bajari et al. (2009) analyze the use of auctions versus negotiations when construction works are procured in the U.S.

Harrington (2008) distinguishes between two broad approaches for cartel discovery. First, there is a structural approach that seeks to identify markets with characteristics that are typically conducive for cartel formation, such as few rivals and homogenous products. Second, there is a behavioral approach that tries to identify suspicious patterns of behavior, which could be either direct evidence of communication, such as illicit meetings and messages, or patterns in prices and quantities that indirectly reveal collusion. Our study lies in the last-mentioned tradition, which Harrington further classifies into four methods:

1. Tests of whether actual behavior is significantly different from that which should follow from competitive behavior. Such tests can be applied to identify the set of firms that may potentially collude.

2. Tests for a structural break in behavior, which could, for example, mark the formation or demise of a cartel.

3. Tests of whether the behavior of a set of firms, suspected to have formed a cartel, differs from that of other firms.

4. Tests of whether a collusion model better describes data than a competitive model.

Depending on data availability, the nature of the cartel and the type of information available, some of these methods may be more useful than others. Because the method we propose is similar in spirit to the third category, we briefly review three previous studies in this tradition.

Porter and Zona (1993) estimate a bid equation for three sets of firms: for those suspected of having formed a cartel, for the remaining firms and for all firms jointly. They subsequently apply a Chow test to the null hypothesis that the estimates are the same for the two subsets and the full set, and they are able to reject the null hypothesis. The implication is that the suspected cartel 
members bid in a way that is significantly different from how other firms bid and that this is an indication of collusion that strengthens the initial presumption.

The second study, also by Porter and Zona (1999) estimate a bid equation where the slope coefficients (and the intercept) are allowed to differ between the suspected cartel firms and the presumably innocent outsiders. If the coefficients differ significantly and in a way that is consistent with collusion, this will again serve to strengthen the initial suspicions of collusion.

Bajari and Ye (2003) depart from the hypothesis that under non-collusive bidding and after controlling for relevant attributes of the firms, bids should be statistically independent. Bids should thus fulfil two criteria; conditional independence and exchangeability. Conditional independence means that bids placed by different firms should be statistically independent when controlling for all factors that affect production costs known to the firm. Exchangeability means that, after controlling for factors determining costs, bids placed by one bidder should be statistically independent of the identity of competing bidders.

Statistical independence is also the main ingredient in the empirical approach suggested in this paper, although with a different estimation technique. Here, spatial econometrics is used to test for collusive behavior, or statistical dependence, across cartel members. Traditionally, the spatial dimension is geographical (e.g., Heijnen, Haan and Soetevent, 2015) but here we apply it to the bidding environment.

\section{Specific features of the studied procurements and the cartel}

The Swedish Road Administration (SRA) ${ }^{5}$ is responsible for the Swedish transport system for state roads, including building, operation and maintenance. The SRA is therefore a frequent buyer of road pavement for construction and repair. During the period for which we have data, 1995 to 2009, the SRA was organized into seven autonomous districts with responsibility for road maintenance within their geographical area. Districts organize their procurement auctions independently.

Following the general principles for public procurement within the $\mathrm{EU}^{6}$, competitive bidding is used by the SRA to allocate the contracts, usually by a first-price sealed-bid auction. ${ }^{7}$ A call for tender stipulates the conditions of the auction and contract specifics as well as a deadline for submission of bids. A single road-pavement procurement auction can include several contracts. If

\footnotetext{
${ }^{5}$ Since 2010, the Swedish Transport Administration. For more information see www.trafikverket.se. Accessed online June 18, 2015.

${ }^{6}$ Directive 2004/17/EC and Directive 2004/18/EC.

${ }^{7}$ This format is less vulnerable to collusion than the second-price sealed bid auction and the English auction. The reason is that under the first-price auction it is more difficult for cartel members to monitor each other (see e.g. Börgers and van Damme, 2004) and it involves stronger incentives for cartel members to deviate from the cartel agreement (Robinson, 1985).
} 
it does, bidding is simultaneous and firms can submit bids for all or for a subset of contracts. Potential bidders are allowed to submit one bid per contract auctioned in one the same procurement. The submitted bids are opened and evaluated at the same time. A typical road pavement call for tender stipulates the road section, the amount of asphalt to be procured and the quality, other contract conditions and principles for supplier selection. Bids submitted on a specific contract are evaluated independently from bids on other contracts in the same procurement. ${ }^{8}$ After the contracts are signed, the bids and evaluation protocol are made public.

The allocation of contracts can in principle be based either on lowest price in combination with mandatory quality criteria or on the economically most advantageous tender (EMAT), see e.g., Bergman and Lundberg (2013). The use of EMAT gives the procurement the character of a multidimensional auction (e.g., Che, 1993), which is also normally combined with mandatory criteria. In the auctions studied, a clear majority of the contracts were allocated to the lowest bidder (Jakobsson, 2007a, 2007b). A few procurements allowed combinatorial bids, i.e., package bids with rebates conditional on the number of contracts won or limits on how many contracts a given firm can accept (see e.g. Lunander and Lundberg, 2013). To prevent a non-solvable allocation of contracts due to overlapping winning package bids, it was compulsory for bidders to submit a stand-alone bid for every contract consisting of a part of a package bid. As combinatorial bidding strategies in comparison to the standard auction are relatively complex, i.e. when formulating a bidding strategy, the bidder not only has to consider the competiveness of the bids of others, but also has to realize that a subset of his/her own bids constitute a potential threat to his/her larger package bids, auctions with combinatorial bids are excluded.

Within the EU, different procurement procedures are allowed. If the total value of the procurement is below the threshold value of nearly SEK 50 million $^{9}$ (about $€ 5$ million), the procurer can use a simplified procedure that is open for everyone to bid and the procuring authorities have the opportunity to initiate negotiations with some of the bidders. For procurements above the threshold, the open procedure is in similarity to the simplified procedure open to everyone, while the rest of the procedures (negotiated and restricted) all have some limitations in bidding, e.g., firms must qualify in order to be given the opportunity to bid. ${ }^{10}$ For purchases of relatively low value authorities are allowed to use a less formal auction format or a so called direct procurement. ${ }^{11}$

\footnotetext{
${ }^{8}$ Unless the auction allows for combinatorial bids, where a bidder can give different prices on bundles of contracts, e.g. offering a lower total price when more contracts are awarded to her.

${ }^{9}$ In 2009, EUR 1 was approximately SEK 10.62 and USD 1 was SEK 7.65.

10 See http://europa.eu/youreurope/business/public-tenders/rules-procedures/index_en.htm for more information. Accessed online June 22, 2015.

11 See e.g. Lundberg (2005) for more about procurement procedures.
} 
The Swedish market for road pavements is worth around SEK 3.5 - 4 billion (about $€$ 330-380 million) per year (SCA, 2009a; Transport Analysis, 2012). The market is dominated by a few large vertically integrated firms, but there are also some small and medium-sized enterprises. This has not always been the case; during the 1980s the market was more fragmented. Gradually, the market became more concentrated through acquisitions, and in recent years, the four largest firms - NCC, Skanska, Svevia, and PEAB Asphalt - have won approximately 80 percent of the contracts, by value. (Transport Analysis, 2012). Before 2009, the state-owned enterprise Svevia was organized as the SRA's in-house production unit, called Vägverket Production ${ }^{12}$, and competed for pavement contracts just as any other firm on the market.

Documentation from the SCA (2009a) suggests that the asphalt cartel began operating in 1993. Initially, three of the large firms met and discussed prices, contrived a bid-rigging scheme and allocated geographical markets between the cartel members. In 1995, Vägverket Produktion joined the cartel. The four cartel members met on a regularly basis to allocate the coming year's contracts and coordinate bidding, for state-government, local-government as well as private procurement of asphalt. The members shared information about volumes and prices. Other firms were compensated for not bidding or for submitting fake bids (complementary bidding), through profitable subcontracts, free services or direct monetary transfers (SCA 2009a). Eventually, the cartel expanded to include nearly all firms in the market.

In September 2001, three former employees of one of the cartel members alerted the SCA of the cartel. They also assisted the SCA with documents and, after un-announced inspections in October the same year and an extensive investigation, nine firms were, in 2003, charged with collusive bidding in Stockholm District Court. The SCA initially claimed SEK 1.6 billion in fines (about $€ 150$ million). This was later lowered to SEK 1.2 billion (about $€ 113$ million). Leniency gave one of the firms immunity from fines, another firm was liquidated before the trial was over and a third firm was found to have played only a marginal role and was therefore acquitted. Six firms, including the four market-dominating firms considered to be the driving forces behind the cartel, were ordered to pay fines amounting to SEK 0.46 billion (about $€ 43$ million).

The convicted firms appealed the decision to the Market Court, as did the SCA, arguing in favor of increased fines. In May 2009, the Market Court confirmed the decision of the District Court and also raised the fines for five of the six appellants. The firm with the largest market share, NCC, was ordered to pay the largest fine of SEK 200 million (about $€ 19$ million). In total, the colluding firms had to pay SEK 0.50 billion in fines (about $€ 47$ million) (SCA 2009b). For a further description of the asphalt cartel, see the SCA (2009a).

\footnotetext{
12 Svevia Ltd. was launched as a separate firm on January 1, 2009. For more information see http://www.svevia.se/omsvevia/historik.html. Accessed online August 4, 2015.
} 


\section{Data}

The datasets used in this study were compiled from SRA procurement documents. ${ }^{13}$ Data for the first period (the cartel period) were previously used in Jakobsson (2007a; 2007b) while data for the post-cartel period were compiled more recently. Together, the two parts of the dataset contain information on most of the SRA's procurements of paving and asphalting works, specifically surfacing works, ${ }^{14}$ between 1995 and 2009. However, as it is possible that the companies under investigation did not directly realize the seriousness of the charges, or that the bidding behavior that had been established within these firms persisted for some time despite efforts to reform, we allow them two years to adapt to these new conditions and, hence, exclude data from 2002 to 2003. In total, the dataset contains information on 233 procurements with 429 contracts and 2,130 bids submitted by 58 individual firms. Descriptive statistics for the variables are displayed in Table 1 below.

Table 1: Descriptive statistics.

\begin{tabular}{|c|c|c|c|c|}
\hline & Mean & Std. dev. & Min & Max \\
\hline \multicolumn{5}{|l|}{ Whole sample, 1995-2001 and 2004-2009 } \\
\hline Bid, SEK per square meter $(b)$ & $1,629.8$ & $7,683.4$ & 6.19 & $92,161.5$ \\
\hline Square meters per contract $\left(\right.$ Area $\left._{c}\right)$ & 52,486 & 48,129 & 9,630 & 154,311 \\
\hline Competition; No of bids $\left(\mathrm{Comp}_{c}\right)$ & 5.42 & 1.50 & 1 & 10 \\
\hline Population density, pop per $\mathrm{km}^{2}\left(\right.$ Dens $\left._{r}\right)$ & 64.52 & 62.42 & 3.29 & 196.9 \\
\hline Number of contracts & 429 & & & \\
\hline Observations & 2130 & & & \\
\hline \multicolumn{5}{|l|}{$1995-2001$ (cartel period) } \\
\hline Bid, SEK per square meter $(b)$ & $1,717.2$ & $8,036.8$ & 12.1 & $92,161.5$ \\
\hline Square meters per contract $\left(\right.$ Area $\left._{c}\right)$ & 42,376 & 39,473 & 9,630 & 154,312 \\
\hline Competition; No of bids $\left(\mathrm{Comp}_{c}\right)$ & 5.61 & 1.47 & 2 & 10 \\
\hline Population density, pop per $\mathrm{km}^{2}\left(\right.$ Dens $\left._{r}\right)$ & 72.28 & 63.47 & 3.30 & 196.9 \\
\hline Number of contracts & 353 & & & \\
\hline Observations & 1830 & & & \\
\hline \multicolumn{5}{|l|}{$2004-2009$ (post-cartel period) } \\
\hline Bid, SEK per square meter $(b)$ & $1,096.8$ & 4,991.6 & 6.19 & 39,300 \\
\hline Square meters per contract $\left(\right.$ Area $\left._{c}\right)$ & 114,161 & 50,202 & 11,027 & 154,312 \\
\hline Competition; No of bids $\left(\mathrm{Comp}_{c}\right)$ & 4.25 & 1.07 & 1 & 7 \\
\hline Population density, pop per $\mathrm{km}^{2}\left(\right.$ Dens $\left._{r}\right)$ & 17.23 & 22.12 & 3.29 & 108.76 \\
\hline Number of contracts & 76 & & & \\
\hline Observations & 300 & & & \\
\hline
\end{tabular}

Note: Bid per square meter is measured in Swedish Kronor (SEK) per square meter in the 2009 price level.

\footnotetext{
${ }^{13}$ When a public contract is signed all procurement documents become public records. The data are based on the call for tender including the bids, technical specification and decision protocol.

${ }^{14}$ Common Procurement Vocabulary (CPV) code 45233222-1.
} 
Our dependent variable, $b_{i}$, is measured as the bid in SEK per square meter of paving. ${ }^{15}$ Optimally we would use asphalt measured in tons because there are variations in how thick the layer of new asphalt is, and the use of square meters could therefore reduce the precision of our estimates. However, because we only use data on relatively non-complex asphalt and paving works (only surfacing), we believe this to be a minor problem. As mentioned earlier, auctions in which combinatorial bidding was allowed are excluded.

As pointed out by, among others, Bajari and Summers (2002) it is important to control for other factors that are likely to affect the cost for completing the contract. Our data includes procurement characteristics and regional characteristics that make it possible to control for differences in the size of the contract, the identity and the number of bidders, and procurement procedure.

Around two thirds of the procurements (71\%) originate from the first period of data, and roughly $82 \%$ of the contracts. The difference is to a large extent explained by a more frequently use of combinatorial bidding during the latter period. ${ }^{16}$

The size of the contract is measured as the square meters of asphalt $\left(A r e a_{c}\right)$ which is assumed to capture potential economies of scale. Contracts are on average larger in the second period, but the average number of bidders $\left(\mathrm{Comp}_{c}\right)$, and the average price per square meter decreases compared to the cartel period.

Two measures are used to capture market structure; the number of bidders on each separate contract $\left(\mathrm{Comp}_{c}\right)$ and population density of the region where the contract is procured (Dens $\left.s_{r}\right)$.

As mentioned previously all procurements are first-price sealed-bid auctions, but they vary with respect to the option to invite potential bidders and negotiations following the tendering process. Procurement procedure is captured by dummy variables taking the value 1 if the procurement procedure is the direct, negotiated, restricted, open, simplified, informal or unknown procedure, respectively. Table 2 shows how frequently the different procedures appear in the data. It also shows the share of contracts by year, geographical region and type of procurement procedure. The vast majority of the contracts are procured using a simplified procedure, 73 and 93 percent for the two time periods, respectively. The majority of the procurements have a value below the EU threshold and, consequently, the simplified procedure is the most commonly applied procedure.

\footnotetext{
${ }^{15}$ All prices are at the 2009 price level.

${ }^{16}$ We removed 43 and 63 procurements for the earlier and the latter period, respectively. Only procurements conducted in or after the year 2000 had combinatorial bidding. Thus we remove 225 and 265 bids from the earlier and the latter period, respectively.
} 
Table 2: Share of contracts per year, region and type of procurement procedure

$\begin{array}{ll}\frac{1995-2001}{\text { Share per year }} & \\ 1995 & 0.208 \\ 1996 & 0.107 \\ 1997 & 0.096 \\ 1998 & 0.183 \\ 1999 & 0.069 \\ 2000 & 0.234 \\ 2001 & 0.102\end{array}$

Share per region

1 - North $\quad 0.094$

2 - Middle $\quad 0.004$

3 - Stockholm $\quad 0.198$

4 - Mälardalen $\quad 0.180$

5 - West $\quad 0.298$

6 - Southeast $\quad 0.122$

7 - Skåne $\quad 0.103$
Share per procedure

Direct $\quad 0.004$

Negotiated $\quad 0.012$

Restricted $\quad 0.009$

Open $\quad 0.189$

Simplified $\quad 0.739$

Informal $\quad 0.007$

Unknown $\quad 0.032$

$\underline{2004-2009}$

Share per year

2004

0.213

2005

0.140

2006

0.203

2007

0.143

2008

0.217

2009

0.083

Share per region

$$
1 \text { - North }
$$

0.540

2 - Middle

3 - Stockholm

4 - Mälardalen

5 - West

6 - Southeast

7 - Skåne
0.153

0.000

0.030

0.200

0.053

0.023
Share per procedure

Direct $\quad 0.040$

Negotiated $\quad 0.000$

Restricted $\quad 0.000$

Open $\quad 0.027$

Simplified $\quad 0.933$

Selective $\quad 0.000$

Unknown $\quad 0.000$

As mentioned, the SRA is divided into seven autonomous districts ${ }^{17}$ and, as shown in Table 2, there is substantial variation in the share of contracts across these districts or regions. The northern region accounts for only 7 percent in the earlier period but almost three quarters in the latter. The difference in shares between the different time periods depends heavily on the marked increase for region North; if we compare the shares between the other regions, it is evident that the difference between the two time periods is much smaller. The reasons for the large increase for the northernmost region is that the data from 1995-1999 only includes regions 3-7, whereas the more recent dataset, 2000-2009, includes procurements from all regions. Therefore, in the first period, the two regions North and Middle only include procurements from the years 2000 and 2001.

Returning to the descriptive statistics in Table 1, the mean of the bid per square meter is significantly higher ${ }^{18}$ during the cartel period, which is expected. The standard deviation is also larger during the cartel period, possibly due to complementary bidding. With complementary bidding a larger difference between the lowest (designated winner) and second lowest cartel bid may be expected. To further explore this, the difference between cartel bids is shown in Table 3.

\footnotetext{
17 The different regions are North (county of Norrbotten and Västerbotten), Middle (county of Jämtland, Västernorrland, Gävleborg, and Dalarna), Stockholm (county of Stockholm and Gotland), Mälardalen (county of Uppsala, Västmanland, Södermanland, Örebro and Östergötland), West (county of Värmland, Västra Götaland and Halland), and Southeast (county of Skåne, Blekinge, Kalmar, Kronoberg, and Jönköping).

${ }^{18}$ Two-sample $t$-test with unequal variances give a $t$-value of $-1.811((\operatorname{Pr}|T|>|t|)=0.0706)$
} 


\begin{tabular}{|c|c|c|c|}
\hline & $\frac{2 \text { nd lowest bid }- \text { lowest bid }}{\text { lowest bid }}$ & $\begin{array}{c}\text { Average bid (excl. lowest) } \\
- \text { lowest bid } \\
\text { lowest bid }\end{array}$ & $\begin{array}{l}\text { Number of } \\
\text { observations }\end{array}$ \\
\hline $\begin{array}{l}1995-2001 \\
\text { Cartel period }\end{array}$ & 0.041 & 0.080 & 342 \\
\hline $\begin{array}{l}2004 \text { - } 2009 \\
\text { Post-cartel period }\end{array}$ & 0.051 & 0.108 & 68 \\
\hline
\end{tabular}

The distribution of cartel bids is, however, not in line with expectations because the second lowest cartel bid is, on average, 4 percent higher during the cartel period and approximately 5 percent higher after the cartel period. The average of all cartel bids (but the lowest) and the lowest cartel bid in percent is also higher during the post-cartel period. If anything, this highlights the importance of controlling for potential cost determinants in screening for collusion.

\section{Econometric setup and empirical approach}

The econometric setup originates from an auction in which potential suppliers, or bidders, compete for at least one contract. The econometric approach for formalizing this is the following: Consider bidders of two types, type $A$ and type $B$, competing for contracts in procurement auctions. Contracts are awarded to the lowest bidder, so that all bids for a specific contract can be assumed to be equal in all relevant aspects apart from price. Bidders of type $A$ form a cartel whereas bidders of type $B$ bid independently of each other. That is, bidding strategies are dependent among type $A$ bidders and are independent among type $B$ bidders as well as across the two types $A$ and $B$.

For simplicity and to illustrate the empirical setup, denote by $b_{i c}$ a bid placed by bidder $i$ on contract $c$. With a total of $n_{C}$ contracts and an average of $n_{A}+n_{B}$ bidders of type $A$ and $B$ on each contract, the total number of bids in the sample is $N=n_{C} \times\left(n_{A}+n_{B}\right)$. The strategy adopted among type $A$ bidders is the simplest possible, namely such that only one type $A$ bidder, bidder $i^{\prime}$ say, place a low bid, $b_{i \prime c}$, on contract $c$ while the rest of type $A$ bidders, $i \neq i^{\prime}, i \in A$ engage in complementary bidding and place high bids. ${ }^{20}$

Next, define a matrix $\mathbf{W}$ of dimension $(N \times N)$ with elements $w$ such that $w_{i c, j c}>0$ if $i \neq j$ and $i, j \in A$ but 0 otherwise. In particular, $w_{i c, j k}=0$ if $c \neq k$, so that bids are independent between contracts (where $c$ and $k$ denote contracts) and $w_{i c, j c}=0$ if $i \in B$ and/or if $j \in B$ so that a non-colluding firm's bids will be independent of bids from all other bidders, whether of type $A$ or $B$. Based on this, consider the regression equation

\footnotetext{
${ }^{19}$ In 2009 prices, calculated for the cartel group also in the post-cartel period.

${ }^{20}$ This assumption is in line with the 2007 findings of the court on the asphalt cartel.
} 


$$
b=\rho \mathbf{W} b+\mathbf{X} \boldsymbol{\beta}+\varepsilon
$$

where $b$ is the vector of all bids placed by both types of bidders, $\mathbf{X}$ is a matrix of relevant covariates, $\varepsilon$ is an error component with the usual properties, and $\rho$ and $\boldsymbol{\beta}$ are parameters to be estimated. Based on the definition of the elements of the spatial weights matrix described above, bidding strategies are by assumption independent among type $B$ bidders and across the two types of bidders, $A$ and $B$, whereas dependence is not ruled out between bidders of type $A$. Accordingly, $\rho \neq 0$ suggests that a bid placed by a cartel member (a bidder of type $A$ ) depends on bids placed by the other cartel members on the same contract. Note also that $w_{i c, i c}=0$ implies that the diagonal of $\mathbf{W}$ consists of zeros only, i.e., assures that $b_{i c}$ will not depend on $b_{i c}$. Moreover, $|\rho|<$ 1 is consistent with Nash equilibrium.

From equation (1) it is evident that the definition of the elements in $\mathbf{W}$ is of crucial importance and deserves special attention. As $\mathbf{W}$ is of dimension $(N \times N)$ it is not possible to estimate its elements together with the other parameters in the model. That is, it is not possible, for instance, to estimate the probability that firm $i$ and $j$ coordinate their bids. Hence, $w_{i c, j c}$ has to be determined a priori based on some criterion reflecting the underlying theory. Applying the simple bidding strategy discussed above, $w_{i c, j c}>0$ for $i \neq j$, and $i, j \in A$, but otherwise $w_{i c, j c}=0$. It is, however, not obvious what value $w_{i c, j c}$ should take to reflect the connectedness between cartel members, and the theory gives no clear guidance on this matter. Following common practice in applied spatial econometrics, the elements are defined such that $w_{i c, j c}=1 /\left(n_{A c}-1\right)$ for $i \neq j$, where $n_{A c}$ is the number of type $A$ bidders on contract $c$ (the lowest bid by a cartel member is excluded, se below). Because the elements in $\mathbf{W}$ are nonnegative, this ensures that all weights are between 0 and 1 .

Moreover, if cartel member $i$ submits the lowest bid among the cartel members on contract $c$, then $w_{i c, j c}=0$ even if $i, j \in A$. This implies that $b_{i c}$ is regressed on the average of the bids placed by the other cartel members - except for the cartel member that placed the lowest bid on contract $c$. By excluding the lowest bid among cartel members the correlation between the other cartel members' bids is expected to be positive.

As the decision on both $b_{i c}$ and $b_{j c}$, with $i \neq j$ and $i, j \in A$, are made within the cartel, the direction of the dependence between $b_{i c}$ and $b_{j c}$ is not obvious. If cartel member $i$ place a low bid, then $j$ has to place a high bid, making $\mathbf{W} b$ endogenous in equation (1). The regression equation (1) is often referred to as a spatial lag model, and it is well known from the spatial econometric literature that OLS estimates will be biased and inconsistent, irrespective of the property of the 
error term (see for instance Anselin, 1988). Instead, maximum likelihood or different types of IV or GMM estimators are frequently used. One advantage with maximum likelihood is that the parameter space for $\rho$ is restricted to $\rho \leq|1|$ which is not generally the case for different IV or GMM estimators, while a drawback is that instrumenting for other potential endogenous variables are not easily done (if not impossible, see Elhorst (2014)). Here, equation (1) is estimated by maximum likelihood using the Stata command spreg. The main reason for this choice is the lack of good instruments for $\mathbf{W} b$; the drawback being that we are not able to instrument for other potentially endogenous variables. However, as our main interest is the "spatial" correlation, our main concern is to get a consistent and unbiased estimate of $\rho$, we accept this drawback. ${ }^{21}$

It is reasonable to assume that the number of potential bidders has a negative effect on $b$. However, information on potential bidders is not easily collected. The number of actual bidders on a specific contract or the number of existing firms within the region where the contract is issued is potential candidates. These measures, however, are not unproblematic. First, a firm located in region $r$ may not be interested in bidding (or have the capacity to bid) for all contracts in region $r$. Second, a contract in region $r$ may or may not be of interest to a firm located in region $s$. Third, the number of bidders or potential bidders is likely to be endogenous in relation to $b$, and relevant instruments are not easily found. Here, the regional population density, Dens $s_{r}$, is used to capture the degree of potential competition on the regional market. We will, however, also estimate equation (1) using the number of bidders on the specific contract, denoted $\operatorname{Comp}_{c}$ instead of Dens $_{r}$ as a measure of potential competition.

The contract size, in square meters, of the area to be paved with asphalt in contract $c$, i.e., Are $_{c}$, is used to capture economies of scale where a negative correlation between $b$ and Area is expected. In addition, regional dummies and time dummies are included in Equation (1) to capture unmeasured regional differences and time trends. The contract size (Area) is significantly larger in the latter time period ${ }^{22}$, whereas the distribution's limits are nearly exactly of the same magnitude. For the post-cartel period, the number of bidders is 4.5 per contract on average - a fall by more than one bidder compared to the previous period, which is a statistically significant ${ }^{23}$ difference. Complementary bidding is a possible explanation, but higher profitability during the cartel period could also have resulted in more firms being willing to incur the cost of bidding.

To explore whether economies of scale are present, we plot the log of the bids per square meter against the contract area, as illustrated in Figure 1.

\footnotetext{
${ }^{21}$ The only potentially endogenous variable used is the measure of potential competition, Comp, defined as the number of bidders on each contract (see the definition below). However, in some specifications, the variable Comp is replaced by population density, which is exogenous.

${ }^{22}$ Two-sample $t$-test with unequal variances give a $t$-value of $10.04((\operatorname{Pr}|T|>|t|)=0.000)$

${ }^{23}$ Two-sample $t$-test with unequal variances give a $t$-value of $17.98((\operatorname{Pr}|T|>|t|)=0.000)$
} 


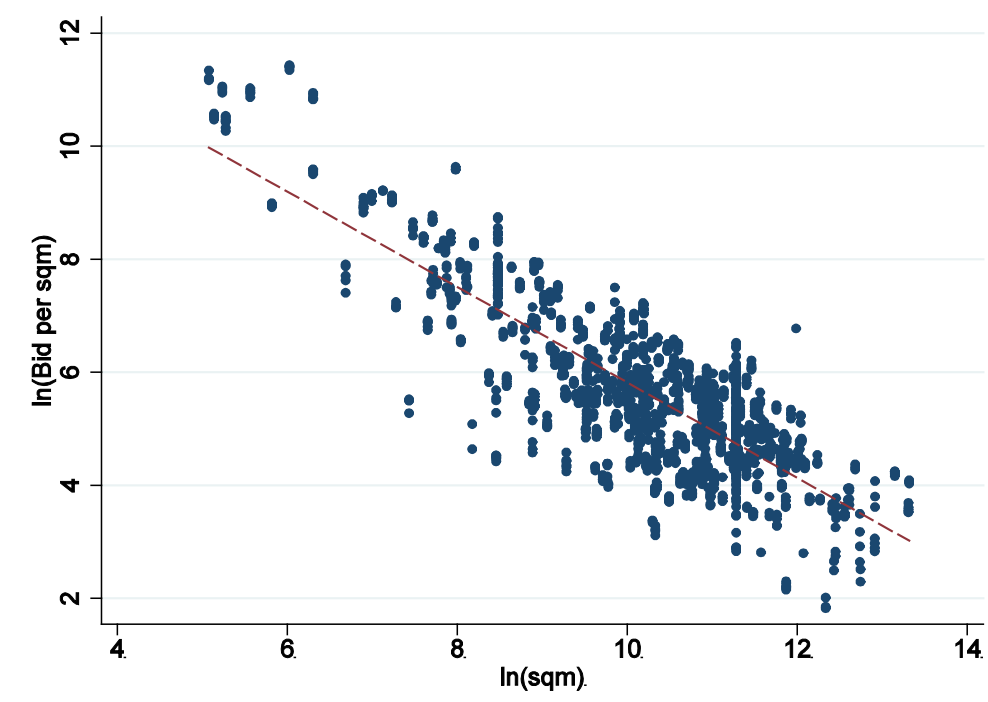

Figure 1: Plot of bid per square meter against square meters (logarithmic values)

The negative relation between the log of bid per square meter and the log of the area of the contract, in square meters, is very close to linear, suggesting a log-linear relationship between $b$ and Area. Therefore, a log specification could give the best model fit, and therefore we will include this in the estimations. The graph also suggests that at least some of the decrease in average cost per unit area between the two periods is due to the larger average contract size in the latter period.

To further explore differences between the cartel and post-cartel periods, we also separate the datasets and compare only the winning bids in a similar manner in Figure 2. Crosses are observations of winning bids during the cartel period and circles represent the non-cartel period. The fitted lines for the winning bids, dotted for post-cartel period and dashed for cartel period, are based on the regression equation $\ln \left(b_{i c}\right)=\alpha+\beta_{\text {Area }} \times \ln \left(\right.$ Area $\left._{r}\right)+\varepsilon$. These two lines are very close to each other. One would perhaps expect to observe higher winning bids during the cartel period, but the lack of a difference between the two periods indicates that we cannot identify a cartel simply by comparing bids. Because cartels are difficult to observe from descriptive statistics and graphs alone, it is therefore important to explore ways of confirming cartel behavior by modelling non-independent bidding behavior. 


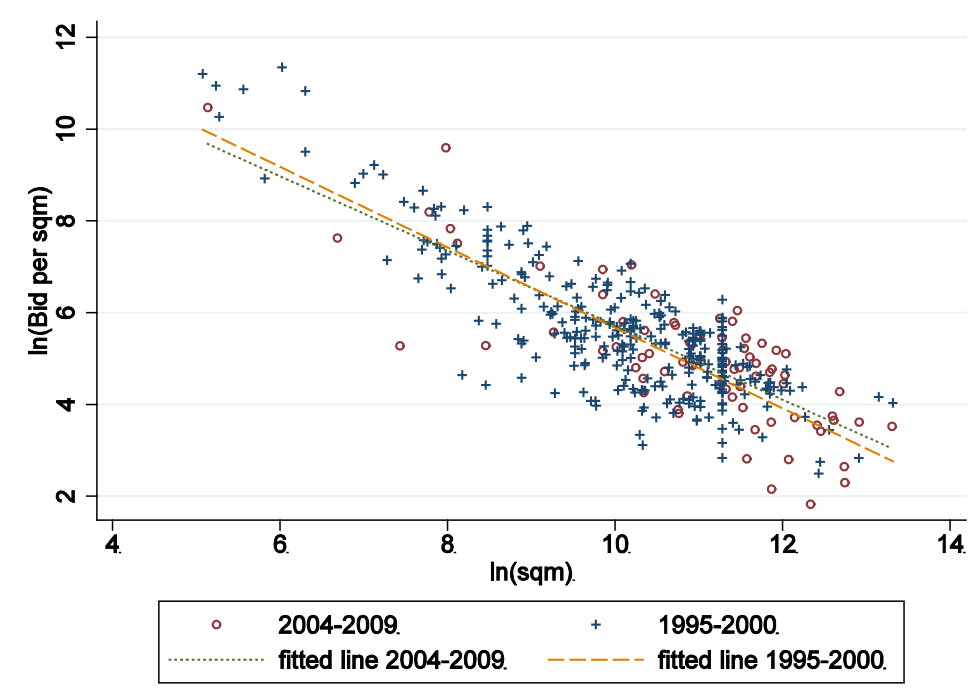

Figure 2: Plot of winning bid per square meter against square meters (logarithmic values)

Based on the discussion above, the bid per square meter submitted by bidder $i, b_{i}$, on contract $c$ is assumed to be determined by the function

$$
b_{i c}=\alpha+\rho \mathbf{W} b_{c}+\beta_{\text {Dens }} \times \text { Dens }_{r}+\beta_{\text {Area }} \times \text { Area }_{c}+\alpha_{t}+\alpha_{r}+\varepsilon_{i c r}
$$

where $i=1, \ldots, N$; the $\alpha$ 's, $\rho$, and $\beta$ 's are parameters to be estimated and $\varepsilon$ is an error term assumed to have the usual properties; $\alpha$ is an intercept; and $\alpha_{t}$ and $\alpha_{r}$ are time and regional fixed effects, respectively. Our prior interest lies in the parameter $\rho$ where $\rho \neq 0$ is taken as evidence for collusive bidding behavior among bidders defined as cartel members by the spatial weights matrix. A significant difference between the estimated values of $\rho$ for the cartel- and post-cartel periods would also suggest a structural shift in bidding behavior between the two periods. In accordance with the court order, it is assumed that the cartel consists of the nine convicted and fined firms only. According to the SCA (2009a), other firms were affected by the cartel and might have bid non-competitively because the cartel offered them side payments or sub-contracts, but we cannot be certain when and for which firms this happened. Indirectly, all firms may have been affected to the extent the cartel succeeded in reducing competitive pressure. To address the potential concern that a positive and significant parameter estimate of $\rho$ for the cartel period is just picking up the effect of unobserved (to us) heterogeneity between the different contracts, a $z$-statistic is applied to test for a structural shift in bidding behavior among (former) cartel members, that is if $\rho_{\text {cartel }} \neq \rho_{\text {post-cartel }}$.

As the linear functional form of equation (2) might be too restrictive (e.g. Figure 1), two alternative specifications, equations (3) and (4), are estimated 


$$
\begin{gathered}
b_{i c}=\alpha+\rho \mathbf{W} b_{c}+\beta_{\text {Dens }} \times \text { Dens }_{r}+\beta_{\text {Dens }^{2}} \times \text { Dens }_{r}^{2}+\beta_{\text {Area }} \times \text { Area }_{r} \\
+\beta_{\text {Area }^{2}} \times \text { Area }_{r}^{2}+\alpha_{t}+\alpha_{r}+\varepsilon_{i c} \\
\ln \left(b_{i c}\right)=\alpha+\rho \mathbf{W} \ln \left(b_{c}\right)+\beta_{\text {lnDens }} \times \ln \left(\text { Dens }_{r}\right)+\beta_{\text {lnArea }} \times \ln \left(\text { Area }_{r}\right)+\alpha_{t} \\
+\alpha_{r}+\varepsilon_{i c}
\end{gathered}
$$

As data on public procurement auctions are scarce, it is useful to develop methods for detecting collusive bidding behavior using a minimum of information and/or information easily collected by the researcher. Therefore, different versions of equations (2) through (4) have also been estimated, where some of the explanatory variables have been excluded.

\section{Results}

Parameter estimates for different specifications of equation (2) - (4) are displayed below, where Table 4 shows the results for the cartel period and Table 5 for the post-cartel period.

For the period before 2002, we expect $\rho$ to be significant and positive, which is also the case in all specifications. This suggests that between 1995 and 2001, the bids placed by the nine companies convicted by the Stockholm District Court for collusive bidding behavior on public contracts violate the conditional independence criteria, which is one of two conditions for statistical independence across bids. Remember that we exclude the lowest cartel bid, so these results suggest that the cartel firms that were not designated to win coordinated their bids, as confirmed by the statistical significance. To take the more conservative stance, based on these results we are not able to rule out the possibility of coordinated bids among cartel firms' not designated to win the contract. Hence, the econometric approach suggested seems to capture coordinated bidding.

Turning to the other covariates, consider first the two measures included to reflect the market structure, Comp and Dens. On a competitive market, both these variables are expected to have a negative impact on $b$. However, during the cartel period a positive correlation exists between $b$ and Comp. A possible interpretation is complementary bidding, although the parameter is only significant in Model 6. An alternative explanation relate to the fact that $\operatorname{Comp}$ is endogenous and, as discussed in Section 5, additional endogenous variables are not easily instrumented for in spatial econometric models estimated by maximum likelihood. Looking instead at the correlation between Dens and $b$ displayed in columns 1, 2 and 5 in Table 4, we observe a negative effect on $b$, in line with expectations. A potential explanation for the negative correlation between Dens and $b$ is that population density does not reflect potential competition but production costs. In 
Sweden, the more densely populated areas are also smaller in physical size which could have a negative effect on production costs. That is, the production plants are located closer to the construction sites, and as transportation of asphalt is costly, this has a negative effect on costs. The variable Area is included to capture potential economies of scale and therefore also expected to have a negative impact on $b$. Presence of economies of scale is confirmed by the negative correlation between Area on $b$ presented in Table 4.

Table 4. Parameter estimates, row standardized weights matrix W. Period 1995 - 2001.

\begin{tabular}{|c|c|c|c|c|c|c|}
\hline & $(1)$ & $(2)$ & (3) & (4) & (5) & (6) \\
\hline$\rho_{\text {cartel }}$ & $\begin{array}{c}0.682 * * * \\
(0.013)\end{array}$ & $\begin{array}{c}0.682 * * * \\
(0.013)\end{array}$ & $\begin{array}{c}0.683 * * * \\
(0.013)\end{array}$ & $\begin{array}{c}0.674^{* * *} \\
(0.013)\end{array}$ & - & - \\
\hline$\rho_{\text {cartel }}(\ln )$ & - & - & - & - & $\begin{array}{c}0.039 * * * \\
(0.005)\end{array}$ & $\begin{array}{c}0.040 * * * \\
(0.005)\end{array}$ \\
\hline$\beta_{\text {Comp }}$ & - & - & $\begin{array}{c}53.057 \\
(97.937)\end{array}$ & $\begin{array}{c}716.501 \\
(472.617)\end{array}$ & - & - \\
\hline$\beta_{\text {Comp }^{2}}$ & - & - & - & $\begin{array}{l}-53.408 \\
(39.434)\end{array}$ & - & - \\
\hline$\beta_{\ln (\mathrm{Comp})}$ & - & - & - & - & - & $\begin{array}{c}0.708^{* * *} \\
(0.067)\end{array}$ \\
\hline$\beta_{\text {Dens }}$ & $\begin{array}{c}-217.238 * * * \\
(80.878)\end{array}$ & $\begin{array}{c}-621.364 \\
(1149.243)\end{array}$ & - & - & - & - \\
\hline$\beta_{\text {Dens } 2}$ & - & $\begin{array}{c}1.058 \\
(3.002)\end{array}$ & - & - & - & - \\
\hline$\beta_{\ln (\text { Dens })}$ & - & - & - & - & $\begin{array}{c}-6.944^{* * *} \\
(1.923)\end{array}$ & - \\
\hline$\beta_{\text {Area }}$ & $\begin{array}{c}-18.852 * * * \\
(2.211)\end{array}$ & $\begin{array}{c}-18.896 * * * \\
(2.21)\end{array}$ & $\begin{array}{c}-18.950 * * * \\
(2.214)\end{array}$ & $\begin{array}{c}-51.692 * * * \\
(4.443)\end{array}$ & - & - \\
\hline$\beta_{\text {Area }^{2}}$ & - & - & - & $\begin{array}{c}0.076 * * * \\
(0.009)\end{array}$ & - & - \\
\hline$\beta_{\ln (\text { Area })}$ & - & - & - & - & $\begin{array}{c}-0.931^{* * *} \\
(0.013)\end{array}$ & $\begin{array}{c}-0.936 * * * \\
(0.013)\end{array}$ \\
\hline \multicolumn{7}{|l|}{ Controls: } \\
\hline - Constant & $\mathrm{Y}$ & $\mathrm{Y}$ & Y & $\mathrm{Y}$ & $\mathrm{Y}$ & $\mathrm{Y}$ \\
\hline - Year & $\mathrm{Y}$ & $\mathrm{Y}$ & $\mathrm{Y}$ & $\mathrm{Y}$ & $\mathrm{Y}$ & $\mathrm{Y}$ \\
\hline - Region & $\mathrm{Y}$ & $\mathrm{Y}$ & $\mathrm{Y}$ & $\mathrm{Y}$ & $\mathrm{Y}$ & $\mathrm{Y}$ \\
\hline - Procedure & $\mathrm{Y}$ & $\mathrm{Y}$ & $\mathrm{Y}$ & $\mathrm{Y}$ & $\mathrm{Y}$ & $\mathrm{Y}$ \\
\hline Wald Chi2 & 153.51 & 153.63 & 146.38 & 222.86 & 5860.84 & 6265.82 \\
\hline $\mathrm{N}$ & 1830 & 1830 & 1830 & 1830 & 1830 & 1830 \\
\hline
\end{tabular}

The positive and significant parameter estimate of $\rho$ indicate that the proposed econometric setup is able to detect suspicious bidding behavior during the cartel period. The next step is to see if bids placed by the nine convicted companies violate the conditional independence criteria during the later period. Parameter estimates corresponding to the period after the early morning raids in 2001 are displayed in Table 5. 
Table 5. Parameter estimates, row standardized weights matrix W. Period $2004-2009$.

\begin{tabular}{|c|c|c|c|c|c|c|}
\hline & (1) & (2) & (3) & (4) & (5) & (6) \\
\hline$\rho_{\text {post-cartel }}$ & $\begin{array}{c}0.006 \\
(0.110)\end{array}$ & $\begin{array}{c}0.005 \\
(0.110)\end{array}$ & $\begin{array}{c}0.006 \\
(0.110)\end{array}$ & $\begin{array}{l}-0.002 \\
(0.110)\end{array}$ & - & - \\
\hline$\rho_{\text {post-cartel }}(\ln )$ & - & - & - & - & $\begin{array}{c}0.027 \\
(0.021)\end{array}$ & $\begin{array}{c}0.025 \\
(0.021)\end{array}$ \\
\hline$\beta_{\text {Comp }}$ & - & - & $\begin{array}{c}141.975 \\
(252.307)\end{array}$ & $\begin{array}{c}-1338.411 \\
(1511.988)\end{array}$ & - & - \\
\hline$\beta_{\text {Comp } p^{2}}$ & - & - & - & $\begin{array}{c}173.746 \\
(173.919)\end{array}$ & - & - \\
\hline$\beta_{\ln (\mathrm{Comp})}$ & - & - & - & - & - & $\begin{array}{c}0.122 \\
(0.172)\end{array}$ \\
\hline$\beta_{\text {Dens }}$ & $\begin{array}{c}-110.250 \\
(2264.080)\end{array}$ & $\begin{array}{c}14749.580 \\
(53540.850)\end{array}$ & - & - & - & - \\
\hline$\beta_{\text {Dens }^{2}}$ & - & $\begin{array}{l}-167.795 \\
(604.196)\end{array}$ & - & - & - & - \\
\hline$\beta_{\ln (\text { Dens })}$ & - & - & - & - & $\begin{array}{c}-6.881 \\
(15.461)\end{array}$ & - \\
\hline$\beta_{\text {Area }}$ & $\begin{array}{c}-8.044 * * \\
(2.916)\end{array}$ & $\begin{array}{c}-8.093^{* *} \\
(2.921)\end{array}$ & $\begin{array}{c}-7.890 * * \\
(2.926)\end{array}$ & $\begin{array}{c}-31.411 * * * \\
(6.376)\end{array}$ & - & - \\
\hline$\beta_{\text {Area }^{2}}$ & - & - & - & $\begin{array}{c}0.051^{* * *} \\
(0.012)\end{array}$ & - & - \\
\hline$\beta_{\ln (\text { Area })}$ & - & - & - & - & $\begin{array}{c}-0.722 * * * \\
(0.033)\end{array}$ & $\begin{array}{c}-0.722^{* * *} \\
(0.033)\end{array}$ \\
\hline \multicolumn{7}{|l|}{ Controls: } \\
\hline - Constant & $\mathrm{Y}$ & $\mathrm{Y}$ & $\mathrm{Y}$ & $\mathrm{Y}$ & $\mathrm{Y}$ & $\mathrm{Y}$ \\
\hline - Year & $\mathrm{Y}$ & $\mathrm{Y}$ & $\mathrm{Y}$ & $\mathrm{Y}$ & $\mathrm{Y}$ & $\mathrm{Y}$ \\
\hline - Region & $\mathrm{Y}$ & $\mathrm{Y}$ & $\mathrm{Y}$ & $\mathrm{Y}$ & $\mathrm{Y}$ & $\mathrm{Y}$ \\
\hline - Procedure & $\mathrm{Y}$ & $\mathrm{Y}$ & $\mathrm{Y}$ & $\mathrm{Y}$ & $\mathrm{Y}$ & $\mathrm{Y}$ \\
\hline Wald Chi2 & 76.40 & 76.50 & 76.79 & 98.32 & 757.39 & 758.43 \\
\hline $\mathrm{N}$ & 300 & 300 & 300 & 300 & 300 & 300 \\
\hline$z$-statistic & 6.11 & 6.11 & 6.11 & 6.09 & 0.56 & 0.69 \\
\hline
\end{tabular}

The results presented in Table 5 indicate a non-significant correlation between bids placed by (former) cartel members on public contracts. Based on these estimates it is not possible to reject the hypothesis that, between 2004 and 2009, bids placed by the convicted companies fulfil the criteria of conditional independence. In combination with the results displayed in Table 4, this suggests that the method proposed is, at least based on the present dataset, able to both detect suspicious bidding behavior and to reject such behavior when it's not likely to be present. Moreover, for specification 1 to $4, \rho$ differ between the two periods. ${ }^{24}$ This is of interest for two reasons: First, a significant difference between the estimated values of $\rho$ for two periods, respectively, addresses the potential concern that a positive and significant parameter estimate is just picking up the effect of unobserved (to us) heterogeneity between the different contracts.

\footnotetext{
${ }^{24}$ This conclusion is based on the z-statistic $z=\left(\rho_{\text {cartel }}-\rho_{\text {post-cartel }}\right) /\left(\left(S E\left(\rho_{\text {cartel }}\right)\right)^{2}+\left(S E\left(\rho_{\text {post-cartel }}\right)\right)^{2}\right)^{0.5}$ presented at the bottom line in Table 5. See Clogg et al. (1995), Paternoster et al. (1995), and Brame et al. (1998).
} 
Such heterogeneity could induce a positive estimate for $\rho$. Second, it suggests that there is a structural shift in bidding behavior among the (former) cartel members and not only a shift in standard deviation. A $\rho$ close to zero for the later period also indicates that the spatial correlation between bids placed by former cartel members on the same contract is close to zero. Together with the results displayed in Table 4, this allows us to conclude that, at least based on the present dataset and the linear specifications, the proposed method is capable of both identifying collusive bidding behavior when such behavior has been verified by court order, and reject conditional dependence in cases where such behavior is unlikely.

Looking at the other covariates, the negative correlation between $b$ and Area confirm the presence of economies of scale also for the latter period. The results presented in Table 5 indicate a positive (in Model 3 and 6) while insignificant effect of the number of bidders on each contract, Comp, on the bids, $b$. As this effect is insignificant, the result suggests absence of complementary bidding during the post-cartel period, which is in line with expectations. Moreover, our estimates suggests a negative (in Model 1 and 5) while insignificant effect of population density, Dens, on the bids, $b$. This is in line with the results for the cartel period, even though the estimate is insignificant. As auctions with combinatorial bidding are excluded, no procurements from the Stockholm area are included in our data for this period, which significantly reduce the variation in Dens, see Table 1. This might explain the insignificant parameter estimate. Anyhow, this result should be interpreted with caution as it is far from robust as the sign of the parameter estimate alter between specifications.

Is this evidence enough? Could other factors drive our results? We have elaborated with several alternative specifications, different time periods (excluding one or several years from the cartel period, to account for transition effects), excluding regions, excluding insignificant variables etc., but the significance of our main parameter $\rho$ stays very much the same for both periods. For instance, to reduce the number of procurements during the cartel period, we excluded, in one set of regressions, the two years with the most procurements, 1998 and 2000. The results from this test, presented in Table A1 in the Appendix, again show positive and significant estimates of $\rho$.

Other factors, such as more firm characteristics (production costs), geographical information (such as geographical distance between firms), local and regional characteristics (such as political preferences reflecting the attitude towards public investments and taxes, local labor market conditions, etc.), could be included in the model. Of course, the inclusion of such information would clearly improve the explanatory power of our models and provide more insights into the bidding process. More information could also help control for potential heterogeneity across type $A$ and $B$ bids on the same contract or between-contract heterogeneity. There are two main reasons 
why we have chosen not to include more information. First, the main purpose has been to test and describe a simple method to be used for (fast) screening of many different markets and procurements for potentially suspicious bidding behavior. Hence, the optimal situation would be a statistical method that could be used for cartel detection with a minimum of information; in this case the bids only. Second, the collection of additional information is costly and time consuming and, in some cases, almost impossible.

Table 6. Parameter estimates, row standardized weights matrix $\mathbf{W}$.

\begin{tabular}{|c|c|c|c|c|}
\hline & Linear model & Logarithmic model & Linear model & Logarithmic model \\
\hline \multicolumn{5}{|l|}{ Cartel period } \\
\hline$\rho_{\text {cartel }}$ & $\begin{array}{c}0.704^{* * *} \\
(0.013)\end{array}$ & $\begin{array}{c}0.150 * * * \\
(0.010)\end{array}$ & $\begin{array}{c}0.688 * * * \\
(0.013)\end{array}$ & $\begin{array}{c}0.063^{* * *} \\
(0.006)\end{array}$ \\
\hline \multicolumn{5}{|l|}{ Controls: } \\
\hline - Constant & $\mathrm{Y}$ & $\mathrm{Y}$ & $\mathrm{Y}$ & $\mathrm{Y}$ \\
\hline - Other covariates & $\mathrm{N}$ & $\mathrm{N}$ & $\mathrm{Y}$ & $\mathrm{Y}$ \\
\hline - Year & $\mathrm{N}$ & $\mathrm{N}$ & $\mathrm{Y}$ & $\mathrm{Y}$ \\
\hline - Region & $\mathrm{N}$ & $\mathrm{N}$ & $\mathrm{Y}$ & $\mathrm{Y}$ \\
\hline - Procedure & $\mathrm{N}$ & $\mathrm{N}$ & $\mathrm{Y}$ & $\mathrm{Y}$ \\
\hline - Firm fixed effects & $\mathrm{N}$ & $\mathrm{N}$ & $\mathrm{Y}$ & $\mathrm{Y}$ \\
\hline Wald Chi2 & - & - & 206.94 & 6425.43 \\
\hline $\mathrm{N}$ & 1830 & 1830 & 1830 & 1830 \\
\hline \multicolumn{5}{|l|}{ Post-cartel period } \\
\hline$\rho_{\text {post-cartel }}$ & $\begin{array}{c}0.002 \\
(0.110)\end{array}$ & $\begin{array}{l}-0.016 \\
(0.033)\end{array}$ & $\begin{array}{c}0.010 \\
(0.110)\end{array}$ & $\begin{array}{c}0.041 \\
(0.022)\end{array}$ \\
\hline \multicolumn{5}{|l|}{ Controls: } \\
\hline - Constant & $\mathrm{Y}$ & $\mathrm{Y}$ & $\mathrm{Y}$ & $\mathrm{Y}$ \\
\hline - Year & $\mathrm{N}$ & $\mathrm{N}$ & $\mathrm{Y}$ & $\mathrm{Y}$ \\
\hline - Region & $\mathrm{N}$ & $\mathrm{N}$ & $\mathrm{Y}$ & $\mathrm{Y}$ \\
\hline - Procedure & $\mathrm{N}$ & $\mathrm{N}$ & $\mathrm{Y}$ & $\mathrm{Y}$ \\
\hline - Firm fixed effects & $\mathrm{N}$ & $\mathrm{N}$ & $\mathrm{Y}$ & $\mathrm{Y}$ \\
\hline Wald Chi2 & - & - & 87.84 & 821.03 \\
\hline $\mathrm{N}$ & 300 & 300 & 300 & 300 \\
\hline$z$-statistic & 6.34 & 4.81 & 6.12 & 0.96 \\
\hline
\end{tabular}

Note: Standard errors within parenthesis. $* * * p<0.001, * * p<0.01, * p<0.05$

Still, parameter estimates from four additional specifications for both the cartel period and the post-cartel period are presented in Table 6. The first two columns show parameter estimates of the very naïve models $b_{i c}=\alpha+\rho \mathbf{W} b_{c}+\varepsilon_{i c}$ and $\ln \left(b_{i c}\right)=\alpha+\rho \mathbf{W} \ln \left(b_{c}\right)+\varepsilon_{i c}$ respectively. In columns three and four, the same covariates as were used in Table 4 and 5 are added (to avoid potential endogeneity, Dens is used instead of Comp) along with firm fixed effects. The general conclusion from Table 6 is that the parameter estimate of main interest, $\rho$, is positive and significant for the cartel period while non-significant (and in one specification negative) for the 
post-cartel period. Moreover, the $z$-statistic presented at the bottom line in Table 6 suggests rejection of the hypothesis that $\rho_{\text {cartel }}=\rho_{\text {post-cartel }}$ for three out of four specifications.

To summarize, the results from our main models, presented in Tables 4 and 5, appear to be robust for a less as well as for a more restrictive specification.

\section{Conclusions}

The aim of this paper has been to present how spatial econometric techniques can be used to detect non-independent bidding between cartel members. The proposed method is applied on a well-known cartel active in the Swedish asphalt paving industry, for which we have data from the cartel period prior to detection as well as from a few years after detection (the post-cartel period). The proposed method confirm a significant and positive correlation between non-winning cartel members' bids during the cartel period which suggests complementary bidding by these firms in order to maintain the appearance of a competitive market. Applying the same method to the postcartel period, no indication of complementary bidding is detected. Moreover, for the linear specifications, the results suggest a structural change in bidding behavior among the former cartel members and the correlation between bids placed by former cartel members to be both nonsignificant and close to zero for the post-cartel period. Hence, the proposed method confirms the existence of cartel behavior during the cartel period and rejects such behavior for the post-cartel period.

The main merit of the proposed method is its simplicity and its relatively small data requirements. If there is suspicion of collusive behavior in a particular market, the proposed method could be used by, for example, competition authorities to, in a fairly simple way, test and screen different markets for conditional independence in bidding for firms that are suspected to collude. However, even though the results presented in this paper are promising, we realize the need for additional testing on other datasets and procurements in order to confirm our results. 


\section{References}

Anselin, L. 1988. Spatial Econometrics: Methods and Models. Springer Science \& Business Media.

Anselin, L. and A. Bera 1998. Spatial dependence in linear regression models with an introduction to spatial econometrics. In: Ullah, A and D. Giles (eds) Handbook of Applied Economics Statistics. Marcel Dekker, New York, 237-289.

Bajari, P. and G. Summers. 2002. Detecting Collusion in Procurement Auctions. Antitrust Law Journal. 70 (1): 143-170.

Bajari, P. and L. Ye. 2003. Deciding between competition and collusion. The Review of Economics and Statistics. 85 (4): 971-989.

Bajari, P., R. McMillan and S. Tadelis. 2009. Auctions versus Negotiations in Procurement: An Empirical Analysis. Journal of Law, Economics and Organization. 25 (2): 372-399 (doi: 10.1093/jleo/ewn002)

Bergman, M. A., and S., Lundberg. 2013. Tender Evaluation and Supplier Selection Methods in Public Procurement. Journal of Purchasing and Supply Management. 19 (2): 73-83.

Brame, R., R. Paternoster, P. Mazerolle, and A. Piquero. 1998. Testing for the Equality of Maximum Likelihood Regression Coefficients Between Two Independent Equations. Journal of Quantitative Criminology. 14: 245-261.

Börgers, T., and E. van Damme. 2004. Auction Theory for Auction Design. In Maarten Janssen (ed.) Auctioning public assets: Analysis and alternatives. pp. 19-63, Cambridge; New York and Melbourne: Cambridge University

Clogg, C.C., E. Petkova, and A. Haritou. 1995. Statistical Methods for Comparing Regression Coefficients Between Models. American Journal of Sociology. 100 (5): 1261-1293.

Connor, J. M., and Y. Bolotova. 2006. The Economics of Cartels, Cartel Policy, and Collusion. Cartel overcharges: Survey and meta-analysis. International Journal of Industrial Organization. 24 (6): 1109-1137.

Cramton, P., and J. A. Schwartz. 2000. Collusive Bidding: Lessons from the FCC Spectrum Auctions. Journal of Regulatory Economics. 17 (3): 229-52.

Cramton, P., and J. A. Schwartz. 2002. Collusive Bidding in the FCC Spectrum Auctions. Contributions to Economic Analysis and Policy. 1 (1): Article 11. 
Directive 2004/17/EC of the European Parliament and of the Council of 31 March 2004 coordinating the procurement procedures of entities operating in the water, energy, transport and postal services sectors (30.04.2004)

Directive 2004/18/EC of the European Parliament and of the Council of 31 March 2004 on the coordination of procedures for the award of public works contracts, public supply contracts and public service contracts (30.04.2004)

Elhorst, J.P. 2014. Spatial Econometrics. From Cross-Sectional Data to Spatial Panels. Springer Heidelberg New York Dordrecht London.

Froeb, L. M., R. A. Koyak and G. J. Werden. What is the Effect of Bid Rigging on Prices?. Economics Letters. 42: 419-423.

Jakobsson, M. 2007a. Bid-rigging in Swedish Procurement Auctions. Mimeo. Department of Economics, Uppsala University, Sweden.

Jakobsson, M. 2007b. Collusion in Procurement Auctions: A Structural Estimation. Department of Economics, Uppsala University, Sweden.

Gupta, S. 2001. The Effect of Bid Rigging on Prices: A Study of the Highway Construction Industry. Review of Industrial Organization. 19 (4): 453-67

Gupta, S. 2002. Competition and Collusion in a Government Procurement Auction Market. Atlantic Economic Journal. 30 (1): 13-25

Grout, P. and S. Sonderegger. 2005. Predicting Cartels. OFT Research Paper 773: Office of Fair Trading, London.

Harrington, J. E. 2008. Detecting cartels, in Handbook of Antitrust Economics. Vol. 1 (Ed. Paolo Buccirossi), MIT Press.

Heijnen, P., M. A. Haan, and A. R. Soetevent. 2015. Screening for Collusion. A Spatial Statistics Approach. Journal of Economic Geography. 15 (2): 417-448.

Lee, I. K. 1999. Non-Cooperative Tacit Collusion, Complementary Bidding and Incumbency Premium. Review of Industrial Organization. 15 (2): 115-134.

Lee, I. K., and K. Hahn. 2002. Bid-Rigging in Auctions for Korean Public-Works Contracts and Potential Damage. Review of Industrial Organization. 21 (1): 73-88.

LeSage, J.P. and R.K. Pace 2009. Introduction to Spatial Econometrics. CRC Press Taylor \& Francis Group, Boca Raton 
Levenstein, M. and V. Y. Suslow. 2006. What Determines Cartel Success? Journal of Economic Literature. 44 (1): 43-95.

Lunander A, and S. Lundberg. 2013. Bids and Costs in Combinatorial and Non-Combinatorial Procurement Auctions. -Evidence from Procurement of Public Cleaning Contracts. Contemporary Economic Policy. 31 (4): 733 - 745.

Lundberg, S. 2005. Restrictions on Competition in Municipal Competitive Procurement in Sweden. International Advances in Economic Research. 11 (3): 353-366.

Paternoster, R., R. Brame, P. Mazerolle, and A. Piquero. 1998. Using the Correct Statistical Test for the Equality of Regression Coefficients. Criminology. 36 (4): 859-866.

Pesendorfer, M. 2000. A Study of Collusion in First-Price Auctions. Review of Economic Studies. 67 (3): 381-411.

Porter, R. H., and J. D. Zona. 1993. Detection of Bid Rigging in Procurement Auctions. Journal of Political Economy. 101 (3): 518-538.

Porter, R. H., and J. D. Zona. 1999. Ohio School Milk Markets: An Analysis of Bidding. RAND Journal of Economics. 30 (2): 263-288.

Porter, R. H. 2005. Detecting Collusion. Review of Industrial Organization. 26 (2): 147-167.

Robinson, M. S. 1985. Collusion and the Choice of Auction. RAND Journal of Economics. 16 (1): 141-145.

Swedish Competition Authority (SCA). 2009a. Bakgrundsmaterial asfaltskartellen, 2009-05-28, Mimeo. In Swedish. Downloadable from www.kkv.se. [In Swedish]

Swedish Competition Authority (SCA). 2009b. Asfaltkartellen fälld i högsta instans, Bakgrundsmaterial - Asfaltskartellen. Press release 2009-05-28. [In Swedish]

Transport Analysis (Trafikanalys). 2012. Anläggningsbranschen - utveckling, marknads-struktur, och konjunkturkänslighet, PM 2012:1. 2012-03-01. [In Swedish] 
Appendix

Table A1: Parameter estimates, row standardized weights matrix, W. Years 1995, 1996, 1997, 1999.

\begin{tabular}{|c|c|c|c|c|c|c|}
\hline & (1) & (2) & (3) & $(4)$ & (5) & (6) \\
\hline$\rho$ & $\begin{array}{c}0.38 * * * \\
(0.02)\end{array}$ & $\begin{array}{c}0.38 * * * \\
(0.02)\end{array}$ & $\begin{array}{c}0.44 * * * \\
(0.02)\end{array}$ & $\begin{array}{c}0.42 * * * \\
(0.02)\end{array}$ & - & - \\
\hline$\rho(\ln )$ & - & - & - & - & $\begin{array}{c}0.03^{* * *} \\
(0.01)\end{array}$ & $\begin{array}{c}0.03^{* * *} \\
(0.01)\end{array}$ \\
\hline$\beta_{\text {Comp }}$ & - & - & $\begin{array}{c}-21.48 \\
(16.33)\end{array}$ & $\begin{array}{c}260.94^{* *} \\
(77.75)\end{array}$ & - & - \\
\hline$\beta_{\text {Comp } 2}$ & - & - & - & $\begin{array}{c}-21.69 * * \\
(6.25)\end{array}$ & - & - \\
\hline$\beta_{\ln (\operatorname{Comp})}$ & - & - & - & - & - & $\begin{array}{c}0.56^{* * *} \\
(0.09)\end{array}$ \\
\hline$\beta_{\text {Dens }}$ & $\begin{array}{c}117.23^{* * *} \\
(12.59)\end{array}$ & $\begin{array}{c}873.00 * * * \\
(178.59)\end{array}$ & - & - & - & - \\
\hline$\beta_{\text {Dens2 }}$ & - & $\begin{array}{c}-1.98 * * * \\
(0.47)\end{array}$ & - & - & - & - \\
\hline$\beta_{\ln (\text { Dens })}$ & - & - & - & - & $\begin{array}{l}7.57 * * \\
(2.30)\end{array}$ & - \\
\hline$\beta_{\text {Area }}$ & $\begin{array}{c}-5.35 * * * \\
(0.64)\end{array}$ & $\begin{array}{c}-5.27 * * * \\
(0.63)\end{array}$ & $\begin{array}{c}-5.20 * * * \\
(0.66)\end{array}$ & $\begin{array}{c}-18.91 * * * \\
(1.71)\end{array}$ & - & - \\
\hline$\beta_{\text {Area }^{2}}$ & - & - & - & $\begin{array}{c}0.09 * * * \\
(0.01)\end{array}$ & - & - \\
\hline$\beta_{\ln (\text { Area })}$ & - & - & - & - & $\begin{array}{c}-0.73^{* * *} \\
(0.02)\end{array}$ & $\begin{array}{c}-0.76 * * * \\
(0.02)\end{array}$ \\
\hline \multicolumn{7}{|l|}{ Controls: } \\
\hline - Constant & $\mathrm{Y}$ & $\mathrm{Y}$ & $\mathrm{Y}$ & $\mathrm{Y}$ & $\mathrm{Y}$ & $\mathrm{Y}$ \\
\hline - Year & $\mathrm{Y}$ & $\mathrm{Y}$ & $\mathrm{Y}$ & $\mathrm{Y}$ & $\mathrm{Y}$ & $\mathrm{Y}$ \\
\hline - Region & $\mathrm{Y}$ & $\mathrm{Y}$ & $\mathrm{Y}$ & $\mathrm{Y}$ & $\mathrm{Y}$ & $\mathrm{Y}$ \\
\hline - Procedure & $\mathrm{Y}$ & $\mathrm{Y}$ & $\mathrm{Y}$ & $\mathrm{Y}$ & $\mathrm{Y}$ & $\mathrm{Y}$ \\
\hline Wald Chi2 & 741.9 & 771.4 & 634.0 & 769.3 & 2419.8 & 2506.4 \\
\hline $\mathrm{N}$ & 1065 & 1065 & 1065 & 1065 & 1065 & 1065 \\
\hline
\end{tabular}

